\title{
Peroxisome proliferator-activated receptor $\alpha$ deficiency modifies glucose handling by isolated mouse adipocytes
}

\author{
C G Walker, M C Sugden, G F Gibbons ${ }^{1}$ and M J Holness \\ Centre for Diabetes and Metabolic Medicine, Institute of Cellular and Molecular Medicine, Queen Mary, University of London, 4 Newark Street, Whitechapel, \\ London E1 2AT, UK \\ ${ }^{1}$ Metabolic Research Laboratory, Oxford Centre for Diabetes, Endocrinology and Metabolism, Nuffield Department of Clinical Medicine, University of Oxford \\ Churchill Hospital, Oxford, UK \\ (Requests for offprints should be addressed to M J Holness; Email: m.j.holness@qmul.ac.uk)
}

\begin{abstract}
Peroxisome proliferator-activated receptor $\alpha(\operatorname{PPAR} \alpha)$ is a transcription factor that regulates enzymes involved in fatty acid (FA) utilisation. PPAR $\alpha$ null mice have recently been demonstrated to have increased whole-body glucose turnover in vivo. This has been attributed to increased glucose uptake by adipose tissue, but the impact of PPAR $\alpha$ deficiency on the characteristics of glucose handling by isolated adipocytes ex vivo is unknown. To determine directly the impact of PPAR $\alpha$ deficiency on adipocyte glucose handling, thereby excluding any influence of humoral/neuronal factors, we examined total glucose metabolism as well as glucose disposition towards alternative fates in epididymal adipocytes isolated from wildtype and PPAR $\alpha$ null mice. Total glucose metabolism (oxidation, incorporation into FA and glycerol moieties of triglyceride
\end{abstract}

(TAG) and conversion to lactate) was measured under basal conditions (low glucose) and 'stimulated lipogenic' conditions (high glucose + insulin). Adipocytes from PPAR $\alpha$ null mice had higher rates of glucose metabolism under both basal and stimulated lipogenic conditions, with increased glucose utilisation both for oxidation and entry into the synthesis of the FA and glycerol components of lipid. In particular, the capacity of adipocytes from PPAR $\alpha$-deficient mice to utilise glucose for synthesis of the glycerol backbone of TAG was greatly enhanced under stimulated (high glucose + insulin) conditions. The increased use of glucose for the glycerol moiety of adipocyte TAG may therefore contribute to, and provide explanation for, enhanced glucose turnover in PPAR $\alpha$ null mice.

Journal of Endocrinology (2007) 193, 39-43

\section{Introduction}

The ability of adipocytes to store triglyceride (TAG) provides animals with a fuel store for use in time of need. In the fed state, insulin increases adipocyte TAG storage by augmenting adipocyte glucose uptake, allowing the production of glycerol-3-phosphate to form the TAG backbone for fatty acid (FA) esterification. Glucose can also be used for the formation of FA de novo. Adipocyte glucose uptake and its conversion to glycerol-3-phosphate are also enhanced by the activation of peroxisome proliferator-activated receptor (PPAR) $\gamma$ (Guan et al. 2002, Picard \& Auwerx 2002, Tordjman et al. 2003, Li et al. 2005), a lipogenic transcription factor.

Contrasting with the role of PPAR $\gamma, \operatorname{PPAR} \alpha$ acts as a lipoxidative transcription factor (Kersten et al. 1999). It is highly expressed in tissues with high rates of FA oxidation, particularly liver, where it augments the expression of enzymes involved in FA catabolism (Braissant et al. 1996). PPAR $\alpha$ is expressed in white adipose tissue, although not highly (Islam et al. 2005). PPAR $\alpha$ deficiency in mice maintained on a high-carbohydrate, low-fat diet results in increased rates of $\mathrm{FA}$ synthesis in adipose tissue in vivo (measured using ${ }^{3} \mathrm{H}_{2} \mathrm{O}$ in vivo), which provides an indication of total flux through the FA synthetic pathway (Islam et al. 2005). Recently, it has been demonstrated that postabsorptive (6 h starved) PPAR $\alpha$ null mice exhibit increased whole-body glucose turnover (production and utilisation), which was attributed to increased rates of glucose uptake/phosphorylation by (gonadal) white adipose tissue (measured using radiolabelled 2-deoxyglucose in vivo; Knauf et al. 2006). This response is unusual since enhanced whole-body glucose turnover is normally accounted for by enhanced glucose uptake (and storage) by skeletal muscle rather than by enhanced adipocyte glucose uptake, since the skeletal muscle mass is considered to be the major site of glucose disposal in vivo and rates of glucose uptake/phosphorylation by white adipose tissue are usually relatively low (Issad et al. 1987, Holness 1996). The mechanism by which adipocytes can account for a large increase in whole-body glucose disposal therefore remains unaccounted for.

In this study, we examined the effects of PPAR $\alpha$ deficiency on glucose handling by isolated adipocytes from $\operatorname{PPAR} \alpha$ null mice. Our aim was to compare the characteristics of glucose handling ex vivo in adipocytes isolated from wild-type and $\operatorname{PPAR} \alpha$ null mice to establish whether increased glucose utilisation in vivo is dependent on systemic or neuronal 
influences. A further objective was to determine the metabolic fate of glucose within the adipocyte.

\section{Materials and Methods}

\section{Materials}

Laboratory reagents were purchased from Roche Diagnostics, Sigma or Fisher Scientific (Loughborough, UK). U $\left[{ }^{14} \mathrm{C}\right]$ D-glucose was purchased from Amersham Biosciences. Type I collagenase was purchased from Worthington Biochemical Corporation (Lakewood, NJ, USA). Wild-type SV/129 mice were purchased from Charles River (Margate, Kent, UK).

\section{Animals}

All procedures performed in this study were approved by the Local Ethics Review Committee of the University of Oxford and were carried out under the authority of the appropriate Home Office (UK) personal and project licences (G F G) in accordance with the Home Office Animals (Scientific Procedures) Act 1986. PPAR $\alpha$ null mice, bred onto a SV/129 genetic background, were provided by Drs J Peters and F J Gonzalez (National Institutes of Health, Bethesda, MD, USA). Wild-type SV/129 mice were used as controls. Male mice (30-40 weeks of age) were housed (four to six per cage) and maintained in a temperature-controlled, air-conditioned environment, subject to a $12 \mathrm{~h}$ light: $12 \mathrm{~h}$ darkness cycle beginning at $2000 \mathrm{~h}$. Mice were allowed free access to water and standard laboratory chow. Mice were sampled between 0900 and $1100 \mathrm{~h}$ and were therefore in the absorptive state.

\section{Tissue sampling}

Mice were anaesthetised by i.p. injection of sodium pentobarbital $(80 \mathrm{mg} / \mathrm{kg})$. Fat pads from the epididymal (EPI), s.c. and perirenal (PR) depots were harvested and weighed and the mice were killed by removal of the heart.

\section{Adipocyte preparation and incubation}

EPI fat pads were collected in Krebs-Ringer-Hepes-buffer (KRHB) containing 3\% insulin-free BSA, $200 \mathrm{nM}$ adenosine and $5 \mathrm{mM}$ glucose (KRHB pH 7.4) and adipocytes were isolated by previously described methods (Rodbell 1964) with minor modifications as detailed in Walker et al. (2006). Adipocyte numbers in the final cell preparation were determined by counting under phase contrast microscopy. Adipocyte size was determined using the program Image $J$ by microscopic measurement of 100-120 cells per preparation using seven preparations. There was no overall difference in mean adipocyte diameter $(74 \pm 10 \mathrm{cf} .76 \pm 4 \mu \mathrm{m})$ or the range of adipocyte diameters (32-204 cf. 24-190 $\mu \mathrm{m}$ ) between EPI adipocytes prepared from fed wild-type and PPAR $\alpha$ null mice.
Glucose fluxes in isolated adipocytes

Adipocytes (100 $\mu \mathrm{l}$ packed cell volume) were pre-incubated in $1 \mathrm{ml}$ glucose-free KRHB under various incubation conditions. Incubations $(4 \mathrm{~h})$ were commenced by the addition of $U\left[{ }^{14} \mathrm{C}\right] \mathrm{D}$-glucose $(4 \mu \mathrm{Ci} / \mathrm{ml})$ with a final glucose concentration of 3 or $20 \mathrm{mM}$. Glucose oxidation was measured by a previously described method (Rodbell 1964) with minor modifications as detailed in Walker et al. (2007a). Incubations, once terminated by the addition of $6 \mathrm{M} \mathrm{H}_{2} \mathrm{SO}_{4}$, released ${ }^{14} \mathrm{CO}_{2}$, which was sequestered by $4 \mathrm{M} \mathrm{NaOH}$, spotted onto filter paper and counted with Optiphase Safe scintillation fluid (Fisher Scientific) in a Beckman L6500 scintillation counter (Beckman Instruments, Urbana, IL,USA). Glucose incorporated into glycerol and the FA fraction of TAG was determined as described previously (Dole \& Meinertz 1960). Lactate production was measured spectrometrically.

\section{Statistical analyses}

Results are presented as the mean \pm s.E.M. Statistical analyses were performed by ANOVA followed by Fisher's post hoc tests for individual comparisons or unpaired (in vivo) or paired (in vitro) Student's t-tests as appropriate. Results were considered significant if $P<0 \cdot 05$.

\section{Results}

\section{Body weight and adiposity in PPAR $\alpha$ null mice}

Body weight and fat pad weight (EPI, PR and s.c. depots) were measured in ad libitum-fed mice. Although body weight was unchanged (Fig. 1A), both EPI and s.c. fat pad masses

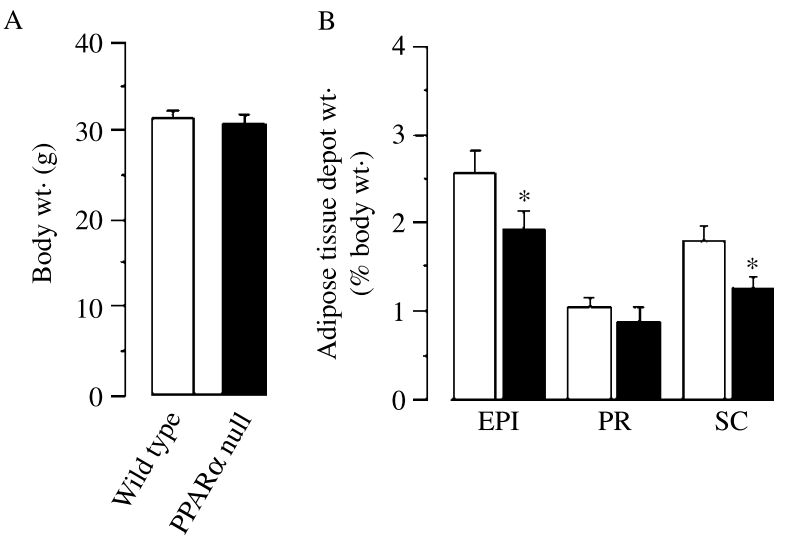

Figure 1 Body weights and adiposity in PPAR $\alpha$ null mice in the fed state. Body weight $(\mathrm{A})$ and fat pad weight (epididymal (EPI), perirenal (PR) and s.c. (SC) depots) (B) were measured in ad libitum-fed wildtype mice (open bars) and PPAR $\alpha$ null mice (closed bars) at a mean age of $34 \pm 1$ weeks. Results are the mean \pm s.E.M. for 30 wild-type mice and 26 PPAR $\alpha$ null mice. Statistically significant differences between wild-type and PPAR $\alpha$ null mice are indicated by $* P<0 \cdot 05$. 
were lower in the PPAR $\alpha$ null mice compared with those of wild-type mice when expressed as the percentage of whole body weight (Fig. 1B).

Adipocyte glucose metabolism ex vivo under 'fasting' conditions

We incubated isolated EPI adipocytes with low glucose and in the absence of insulin to mimic the fasting extracellular milieu. Absolute rates of glucose oxidation to $\mathrm{CO}_{2}$ by adipocytes from the PPAR $\alpha$ null mice under low-glucose conditions were $2 \cdot 3$-fold higher than those of adipocytes from the wild-type mice (Fig. 2A). Adipocytes from the PPAR $\alpha$ null mice also had $2 \cdot 5$-fold increased rates of lactate production compared with those from the wild-type mice (Fig. 2B). Thus, both glucose oxidation and its conversion to lactate are favoured in adipocytes from PPAR $\alpha$ null mice under 'fasting' conditions. PPAR $\alpha$ deficiency was also associated with a 13 -fold increase in the use of glucose for FA synthesis compared with wild-type mice under lowglucose conditions (Fig. 3A), indicating preferential utilisation of glucose-derived acetyl-CoA for FA synthesis. For both genotypes, glucose incorporation into the glycerol moiety of TAG was quantitatively of much greater importance than its use for FA synthesis de novo. For adipocytes from wild-type mice, incorporation of glucose into the glycerol backbone of TAG was $14 \cdot 2$-fold higher than its use for FA synthesis. Glucose incorporation into glycerol was $2 \cdot 8$-fold higher $(P<0 \cdot 05)$ for adipocytes from PPAR $\alpha$ null mice compared with wild-type mice (Fig. 3A). It is concluded that PPAR $\alpha$ deficiency causes stable changes in adipocyte glucose handling such that there is increased use of glucose for the synthesis of both glycerol-3-phosphate and FA for TAG synthesis, and that PPAR $\alpha$ deficiency permits significant rates of de novo FA synthesis and esterification to occur even under conditions of low extracellular glucose.

Effects of insulin stimulation on adipocyte glucose utilisation and disposition

Using isolated EPI adipocytes, we also measured glucose handling by adipocytes under stimulated lipogenic conditions by incubating in $20 \mathrm{mM}$ glucose with $16 \mathrm{nM}$ insulin. Incubation under glucose +insulin-stimulated conditions resulted in only a modest (34\%) non-significant increase in glucose oxidation by adipocytes isolated from wild-type mice, whereas there was a much more marked increase $(170 \%$; $P<0 \cdot 05)$ in glucose oxidation by adipocytes from PPAR $\alpha$ null mice (Fig. 2, compare A and C). As a consequence, the amount of glucose oxidised in adipocytes of the PPAR $\alpha$ null mice was $2 \cdot 9$-fold that of wild-type mice under stimulated incubation conditions (Fig. 2C). Production of lactate was stimulated under the lipogenic incubation conditions by 4.4 -fold $(P<0.05)$ in adipocytes of wild-type mice and $3 \cdot 5$-fold $(P<0 \cdot 05)$ in adipocytes of PPAR $\alpha$ null mice (Fig. 2 , compare $\mathrm{B}$ and $\mathrm{D})$.
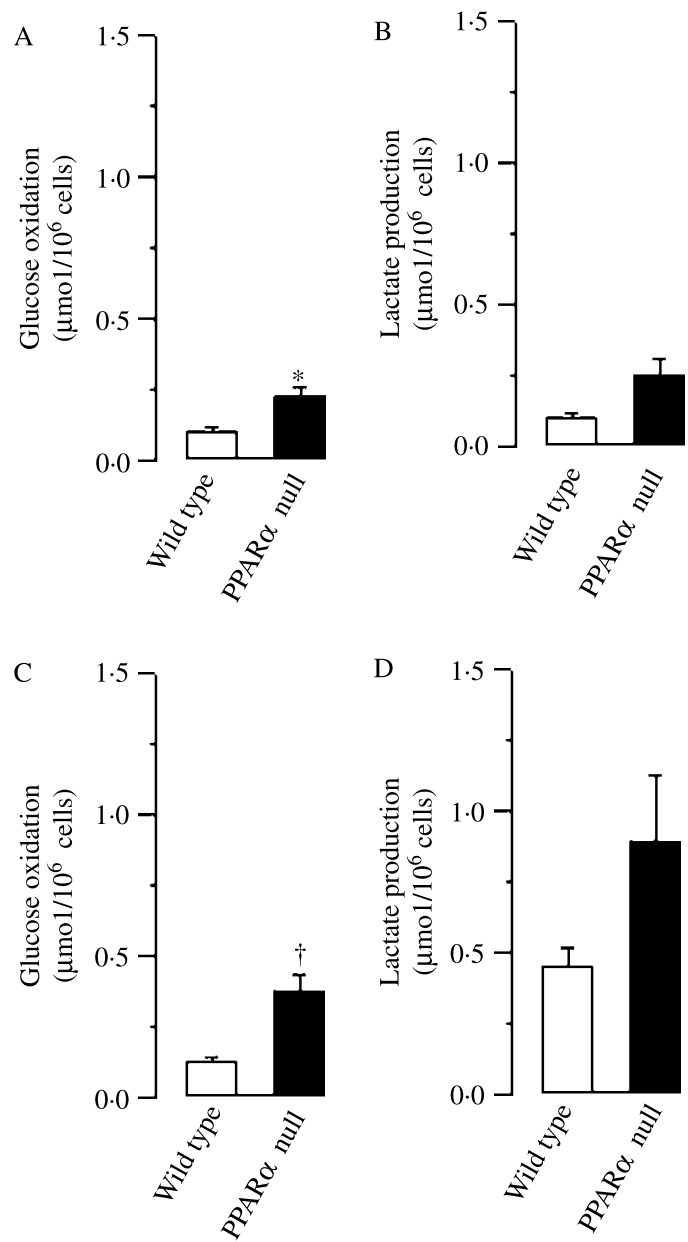

Figure 2 Adipocyte glucose oxidation and production of lactate. Adipocytes (100 $\mu$ l packed cell volume) were pre-incubated in $1 \mathrm{ml}$ glucose-free KRHB under various incubation conditions. Incubations were commenced by the addition of $U\left[{ }^{14} \mathrm{C}\right] \mathrm{D}$-glucose $(4 \mu \mathrm{Ci} / \mathrm{ml})$. (A) and (B) Data obtained with EPI adipocytes from ad libitum-fed wild-type mice (open bars) and PPAR $\alpha$ null mice (closed bars) incubated at $3 \mathrm{mMglucose}$ in the absence of insulin. (C) and (D) Data obtained with EPI adipocytes from ad libitum-fed wild-type mice (open bars) and PPAR $\alpha$ null mice (closed bars) incubated at $20 \mathrm{mM}$ glucose in the presence of $16 \mathrm{nM}$ insulin. Glucose oxidation was measured by previously described methods (Rodbell 1964) with minor modifications as detailed in Walker et al. (2007a). Lactate production (B and D) was measured spectrophotometrically. Results are the mean \pm s.E.M. for nine adipocyte preparations from wild-type mice and eight adipocyte preparations from PPAR $\alpha$ null mice.

Statistically significant differences between adipocytes from wildtype and PPAR $\alpha$ null mice are indicated by ${ }^{*} P<0 \cdot 05$ and ${ }^{+} P<0 \cdot 01$.

Whereas glucose incorporation into FA was very low with adipocytes from wild-type mice incubated at low glucose, a $7 \cdot 3$-fold increase $(P<0 \cdot 05)$ was observed under conditions of stimulation by high glucose + insulin (Fig. 3, compare A and B). Glucose incorporation into FA was less markedly affected by switching from low glucose to high glucose + insulin with adipocytes from PPAR $\alpha$ null mice: a $14 \%$ increase only. Switching from low glucose to high glucose + insulin elicited 

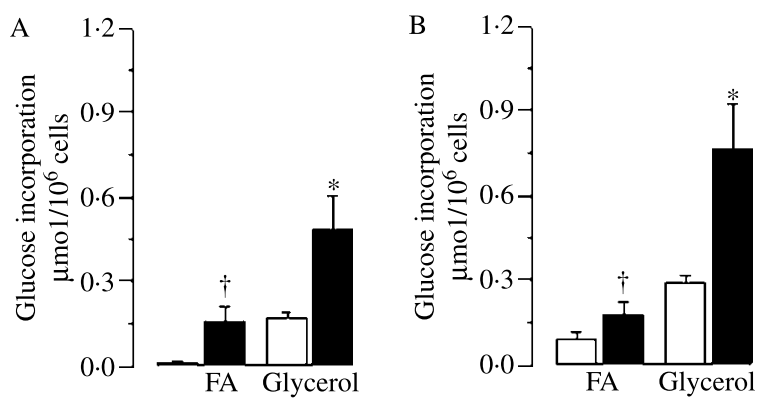

Figure 3 Glucose incorporation into the FA and glycerol moieties of TAG. Glucose incorporation into the FA and glycerol moieties of TAG are shown for adipocytes isolated from wild-type mice (open bars) and PPAR $\alpha$ null mice (closed bars). Data obtained with EPI adipocytes incubated at $3 \mathrm{mM}$ glucose in the absence of insulin are shown in A. (B) Data obtained with EPI adipocytes incubated at $20 \mathrm{mM}$ glucose in the presence of $16 \mathrm{nM}$ insulin. Glucose incorporation into the FA and glycerol moieties of TAG was determined by a previously described method (Dole \& Meinertz 1960). Results are the mean \pm S.E.M. for nine adipocyte preparations from wild-type mice and eight adipocyte preparations from PPAR $\alpha$ null mice. Statistically significant differences between adipocytes from wild-type and PPAR $\alpha$ null mice are indicated by $* P<0.05$ and ${ }^{+} P<0 \cdot 01$.

a $1 \cdot 7$-fold increase $(P<0 \cdot 01)$ in incorporation of glucose into the glycerol backbone of TAG with adipocytes from wildtype mice; an increase of similar magnitude was observed with adipocytes from $\operatorname{PPAR} \alpha$ null mice $(1 \cdot 6$-fold; Fig. 3$)$. Thus, incorporation of glucose into the glycerol backbone of TAG remained significantly greater than its contribution to the FA moiety of TAG in the stimulated state for both genotypes, but adipocytes from $\operatorname{PPAR} \alpha$ null mice were characterised by markedly higher rates of glucose incorporation into the glycerol moiety of TAG (Fig. 3B). A 1.5-fold increase in lipolysis (assessed by glycerol release) was seen in adipocytes from PPAR $\alpha$ null mice compared with wild-type mice $(1580 \pm 460$ cf. $1056 \pm 433 \mathrm{nmol}$ glycerol released per $10^{6}$ cells). Thus, increased availability of FA may have allowed the increased formation of TAG, incorporating the glycerol backbone generated from glucose.

\section{Discussion}

Recent research has demonstrated that postabsorptive $(6 \mathrm{~h}$ starved) PPAR $\alpha$ null mice show increased whole-body glucose turnover (production and utilisation; Knauf et al. 2006). The latter was attributed to an increased rate of glucose uptake by white adipose tissue (measured using radiolabelled 2-deoxyglucose in vivo; Knauf et al. 2006). In the present study, adipocyte glucose handling was examined ex vivo using isolated adipocytes from age-matched PPAR $\alpha$ null and wildtype mice. We delineated the characteristics of adipocyte glucose handling ex vivo in PPAR $\alpha$ null mice, demonstrating that increased glucose utilisation is intrinsic to the adipose tissue itself, either as a direct result of PPAR $\alpha$ deficiency in the adipocyte or due to conditioning from the whole-body $\operatorname{PPAR} \alpha$ phenotype. We also show that $\operatorname{PPAR} \alpha$ deficiency allows a much higher rate of glucose incorporation into the glycerol backbone of TAG, both under conditions of insulin stimulation and also under basal conditions.

In the paper by Knauf et al. (2006), white adipocytes were found to be larger as were the adipose tissue depots of PPAR $\alpha$ null mice, whereas we have consistently found adipose depots to be smaller in the PPAR $\alpha$ null mice colony that we utilise (Walker et al. 2007b). This may be a result of difference in age, as the mice in the present study were 30-40 weeks of age compared with those used in the study by Knauf et al. (2006) that were only 14 weeks of age. Nevertheless, our results of increased adipocyte glucose metabolism in vitro consolidate the findings of Knauf et al. (2006) of increased glucose uptake by adipose tissue in vivo. We believe that this indicates that, regardless of adipocyte size, these changes in adipocyte glucose metabolism may be intrinsic to the $\operatorname{PPAR} \alpha$ null phenotype and consistent among the colonies of PPAR $\alpha$ null mice. In the fed state, adipocyte TAG storage is promoted by augmenting adipocyte glucose uptake, glycerol-3-phosphate formation and FA synthesis de novo. These events are co-ordinated by insulin and PPAR $\gamma$ activation. PPAR $\alpha$ signalling is regarded as minimal in the well-fed state, and the $\operatorname{PPAR} \alpha$ null mouse (a model of PPAR $\alpha$ deficiency), when maintained on standard high-carbohydrate/low-fat diet, does not exhibit any obvious metabolic phenotype. However, when PPAR $\alpha$ null mice are maintained on a high-fat diet, they become more obese than their wild-type counterparts and are protected from the development of dietary lipidinduced insulin resistance (Guerre-Millo et al. 2001). The absence of PPAR $\alpha$, by lowering the rate of FA oxidation in tissues that normally exhibit high rates of FA uptake and oxidation (e.g. liver, skeletal muscles), was proposed to favour glucose oxidation in these tissues and, therefore, glucose clearance when a high-fat diet was provided. PPAR $\alpha$ is expressed in white adipose tissue from ad libitum-fed wildtype mice (Islam et al. 2005) and here we demonstrate that glucose utilisation, both for oxidation and entry into lipid synthesis, is augmented in white adipocytes prepared from fed $\operatorname{PPAR} \alpha$-deficient mice.

The mechanism by which glucose metabolism, in particular lipogenesis, is up-regulated in the $\operatorname{PPAR} \alpha$ null mice is not clear. Although rates of flux through the fatty acid pathway (measured in vivo by ${ }^{3} \mathrm{H}$ incorporation from ${ }^{3} \mathrm{H}_{2} \mathrm{O}$, which measures total lipogenesis from all available substrates) are greatly increased in EPI adipose tissue of ad libitum-fed $\operatorname{PPAR} \alpha$ null mice, gene expression of the lipogenic transcription factor SREBP-1c and lipogenic gene acetylCoA carboxylase has previously been shown to be lower (Islam et al. 2005). Previous studies have also demonstrated increased GLUT4 expression in adipose tissue of PPAR $\alpha$ null mice in the fasting (but not in the fed) state (Knauf et al. 2006). Thus, altered GLUT4 expression is unlikely to underlie the changes observed in glucose metabolism in the present experiments when adipocytes prepared from fed mice 
are stimulated with insulin. However, as changes in GLUT4 responsiveness to insulin can be manipulated within $20 \mathrm{~min}$ in isolated adipocytes (Haruta et al. 1995), it is possible that PPAR $\alpha$ status may have altered GLUT4 recruitment during the incubation, contributing to the observed changes in glucose metabolism.

While re-expression of $\operatorname{PPAR} \alpha$ in the livers of null mice does not lower whole-body glucose turnover (and by implication adipocyte glucose utilisation) in vivo, infusion of the PPAR $\alpha$ agonist WY14,643 into the lateral ventricle of the brain for $3 \mathrm{~h}$ specifically lowers adipose tissue glucose uptake/phosphorylation in vivo (Knauf et al. 2006). It was proposed that the effect of $\operatorname{PPAR} \alpha$ activation in the brain to lower glucose uptake might be exerted through regulation of cerebral neuropeptide expression by $\operatorname{PPAR} \alpha$ activation. Although we did not directly investigate the impact of altered neuro/hormonal stimulation on adipocyte function in vitro, our data show that increased glucose metabolism in adipocytes from PPAR $\alpha$ null mice is stable to adipocyte preparation and incubation, and thus does not require a sustained neuro/hormonal stimulus.

In summary, our data demonstrate that glucose utilisation, both for oxidation and entry into lipid synthesis, is augmented in white adipocytes from PPAR $\alpha$ null mice. In particular, the capacity of adipocytes from PPAR $\alpha$-deficient mice to utilise glucose for synthesis of the glycerol backbone of TAG is greatly enhanced under stimulated (high glucose + insulin) conditions. The increased use of glucose for the glycerol moiety of adipocyte TAG may therefore contribute to, and provide explanation for, enhanced glucose turnover in PPAR $\alpha$ null mice.

\section{Acknowledgements}

We are grateful to Diabetes UK (BDA: RDA04/0002863 and BDA:RD03/0002725) for financial support. The authors declare that there is no conflict of interest that would prejudice the impartiality of this scientific work.

\section{References}

Braissant O, Foufelle F, Scotto C, Dauca M \& Wahli W 1996 Differential expression of peroxisome proliferator-activated receptors (PPARs): tissue distribution of PPAR-alpha, -beta, and -gamma in the adult rat. Endocrinology 137 354-366.

Dole VP \& Meinertz H 1960 Microdetermination of long-chain fatty acids in plasma and tissues. Journal of Biological Chemistry 235 2595-2599.
Guan HP, Li Y, Jensen MV, Newgard CB, Steppan CM \& Lazar MA 2002 A futile metabolic cycle activated in adipocytes by antidiabetic agents. Nature Medicine 8 1122-1128.

Guerre-Millo M, Rouault C, Poulain P, Andre J, Poitout V, Peters JM, Gonzalez FJ, Fruchart JC, Reach G \& Staels B 2001 PPAR-alpha-null mice are protected from high-fat diet-induced insulin resistance. Diabetes $\mathbf{5 0}$ 2809-2814.

Haruta T, Morris AJ, Rose DW, Nelson JG, Mueckler M \& Olefsky JM 1995 Insulin-stimulated GLUT4 translocation is mediated by a divergent intracellular signaling pathway. Journal of Biological Chemistry 270 27991-27994

Holness MJ 1996 Impact of early growth retardation on glucoregulatory control and insulin action in mature rats. American Journal of Physiology, Endocrinology and Metabolism 270 E946-E954.

Islam KK, Knight BL, Frayn KN, Patel DD \& Gibbons GF 2005 Deficiency of PPARalpha disturbs the response of lipogenic flux and of lipogenic and cholesterogenic gene expression to dietary cholesterol in mouse white adipose tissue. Biochimica et Biophysica Acta 1734 259-268.

Issad T, Penicaud L, Ferre P, Kande J, Baudon MA \& Girard J 1987 Effects of fasting on tissue glucose utilization in conscious resting rats. Major glucosesparing effect in working muscles. Biochemical Journal 246 241-244.

Kersten S, Seydoux J, Peters JM, Gonzalez FJ, Desvergne B \& Wahli W 1999 Peroxisome proliferator-activated receptor alpha mediates the adaptive response to fasting. Journal of Clinical Investigation 103 1489-1498.

Knauf C, Rieusset J, Foretz M, Cani PD, Uldry M, Hosokawa M, Martinez E, Bringart M, Waget A, Kersten S et al. 2006 PPAR $\alpha$ null mice have increased white adipose tissue glucose utilization, GLUT4, and fat mass role in liver and brain. Endocrinology 147 4067-4078.

Li G, Zhang Y, Wilsey JT \& Scarpace PJ 2005 Hypothalamic proopiomelanocortin gene delivery ameliorates obesity and glucose intolerance in aged rats. Diabetologia 48 2376-2385.

Picard F \& Auwerx J 2002 PPAR(gamma) and glucose homeostasis. Annual Review of Nutrition 22 167-197.

Rodbell M 1964 Metabolism of isolated fat cells. I. Effects of hormones on glucose metabolism and lipolysis. Journal of Biological Chemistry 239 375-380.

Tordjman J, Khazen W, Antoine B, Chauvet G, Quette J, Fouque F, Beale EG, Benelli C \& Forest C 2003 Regulation of glyceroneogenesis and phosphoenolpyruvate carboxykinase by fatty acids, retinoic acids and thiazolidinediones: potential relevance to type 2 diabetes. Biochimie $\mathbf{8 5}$ 1213-1218.

Walker CG, Bryson JM, Hancock DP \& Caterson ID 2007a Leptin secretion is related to glucose derived lipogenesis in isolated adipocytes. International Journal of Obesity In press.

Walker CG, Holness MJ, Gibbons GF \& Sugden MC $2007 b$ Fasting-induced increases in Aquaporin 7 and adipose triglyceride lipase mRNA expression in adipose tissue are attenuated by peroxisome proliferator-activated receptor deficiency. International Journal of Obesity In press.

Received in final form 31 January 2007

Accepted 2 February 2007

Made available online as an Accepted Preprint

5 February 2007 